\title{
ПРАВО НА ОБРАЗОВАНИЕ И МЕЖДУНАРОДНЫЕ СТАНДАРТЫ ОРГАНИЗАЦИИ ОБЪЕДИНЕННЫХ НАЦИЙ
}

\author{
Статья подготовлена при поддержке РГНФ, грант № 01201455235
}

Аннотация. В статье рассматриваются основные международные документы, принятые в системе ООН и составляюшие основу универсальных международных стандартов в сфере образования. В статье анализируются положения основных конвенциий и деклараций, принятых Генеральной Ассамблеей ООН и посвящуенных вопросам образования. Особое внимание уделяется проблеме недискриминации в сфере образования по признакам расовой, национальной, религиозной принадлежности, пола, языка, состояния здоровья. Исследуются международные основы права на образование заключенных и лии с ограниченныли возможностями. В результате проведенного исследования формулируется вывод о развитии в рамках ООН системы универсальных стандартов, обеспечивающих общие и специальные гарантии права каждого на образование, которое становится в современном мире одним из наиболее значимых в комплексе прав и основных свобод человека. Отмечается, что система универсальных межсународных стандартов ООН в сфере образования позволяет создать условия для реализации в универсальном масштабе права каждого на качественное и доступное образование.

Ключевые слова: международные организации, право на образование, Организация Объединенных Наций, равноправие, недискриминация, международные документы, международные стандарты, специильные гарантии права, основные свободы человека, образование.

Abstract: The article concerns basic legal documents within the UNO system, forming the basis for the universal international standards in the sphere of education. The author analyzes the provisions of basic conventions and declarations, which were adopted by the General Assembly of the UNO on the issues of education. Special attention is paid to the problem of non-discrimination in the sphere of education based on racial, national and religious background, sex, language, health condition. The author studies the fundamentals of international law regarding education of convicted persons and persons with limited abilities. As a result of the study, the author formulates the conclusion on the development within the UN framework of the system of universal standards, guaranteeing general and specific rights of every person for an education, as one of the most significant rights within the complex of basic human rights and freedoms. It is noted that the system of universal international standards of the UNO in the sphere of education allows to form the conditions for the implementation of a right of every person for the access to quality education on an universal scale.

Keywords: international organizations, right to education, the United Nations Organization, equal rights, non-discrimination, international documents, international standards, special legal guarantees, basic human freedoms, education.

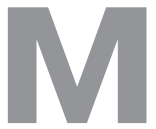

еждународное право становится все более значимым и активным регулятором правоотношений, даже тех, которые традиционно относились к домену внутригосударственного права ${ }^{1}$. Несмотря на продолжающуюся критику и необходимость существенной модернизации организационной структуры и форм и направлений деятельности,

\footnotetext{
${ }^{1}$ Каламкарян Р.А., Мигачев Ю.И. Международное право как регулятор современных международно-правовых отношений // Государство и право. - 2013. - 11. - С. 46-59
}

Организация Объединенных Наций продолжает играть основополагающую роль в деле координации сотрудничества государств в самых различных сферах. Право на образование как социальная ценность, входящая в систему прав второго поколения, получило всеобщее признание и закрепление после Второй Мировой войны не только в национальных конституциях и законодательстве, но и в международно-правовых документах. Особую роль в процессе универсального признания, создания гарантий и механизма защиты права на образование 
сыграла и продолжает играть Организация Объединенных Наций ${ }^{2}$. Право на образование было включено в качестве одного из основополагающих в текст Всеобщей Декларации прав человека 1948 г. ${ }^{3}$, принятой Генеральной Ассамблеей ООН 10 декабря. Так статья 26 (часть 1) Всеобщей Декларации прав человека устанавливает минимальные стандарты образования: «Каждый человек имеет право на образование. Образование должно быть бесплатным, по меньшей мере в том, что касается начального и общего образования. Начальное образование должно быть обязательным. Техническое и профессиональное образование должно быть общедоступным, и высшее образование должно быть одинаково доступным для всех на основе способностей каждого». Часть вторая данной статьи определяет гуманитарные основы системы образования, которое «должно быть направлено к полному развитию человеческой личности и к увеличению уважения к правам человека и основным свободам», содействовать «взаимопониманию, терпимости и дружбе между всеми народами, расовыми и религиозными группами, и должно содействовать деятельности Организации Объединенных Наций по поддержанию мира», а часть третья гарантирует родителям «право приоритета в выборе вида образования для своих малолетних детей». Несмотря на универсальное признание, данные положения имеют декларативный характер. Лишь спустя 18 лет Объединенные Нации смогли разработать и принять юридически обязывающий Международный пакт об экономических, социальных и культурных правах ${ }^{4}$ (принятый резолюцией 2200 А (XXI) Генеральной Ассамблеи от 16 декабря 1966 г., вступил в силу 3 января 1976 года). Статья 13

\footnotetext{
${ }^{2}$ Комаров В.В. Образование в ландшафте ООН // Экономика образования. 2013. № 5 (78). С. 12-23

${ }^{3}$ Всеобщая декларация прав человека (Принята 10.12.1948 г. Генеральной Ассамблеей ООН) // Российская газета. 1995. 5 апреля; Права человека. Сборник международных договоров. Нью-Йорк: Организация Объединенных Наций, 1978. C. $1-3$.

${ }^{4}$ Международный пакт от 16.12.1966 г. «Об экономических, социальных и культурных правах» // Бюллетень Верховного Суда РФ. 1994. № 12. (Пакт ратифицирован Указом Президиума ВС СССР от 18.09.1973 г. № 4812-VIII.)
}

Пакта устанавливает более развернутую и юридически обязывающую систему гарантий права на образование. Прежде всего, она констатирует признание государствами-участниками «право каждого человека на образование», подчеркивая гуманистическую направленность образования «на полное развитие человеческой личности и ее достоинства», а также «укрепление уважения к правам человека и основным свободам». Кроме того, «образование должно дать возможность всем быть полезными участниками свободного общества, способствовать взаимопониманию, терпимости и дружбе между всеми нациями, всеми расовыми, этническими и религиозными группами и содействовать работе Организации Объединенных Наций по поддержанию мира».

Далее, государства устанавливают минимальные стандарты начального, среднего и высшего образования. Так, начальное образование должно быть всеобщим, обязательным и бесплатным, а в случае его отсутствия поощряется или интенсифицируется элементарное образование. В отношении среднего, в том числе профессионально-технического, образования гарантируется открытость и доступность для всех, в том числе путем «постепенного введения бесплатного образования». Наконец, государства обязуются обеспечить всеобщую равную доступность в соответствии со способностями, в том числе путем «постепенного введения бесплатного образования». Таким образом, для всех уровней организации образования определяются такие принципы как всеобщность, доступность, равноправие, открытость, а также бесплатность как цель для среднего и высшего уровней образования и как нормативная обязанность для начального образования, которое к тому же должно стать обязательным.

Кроме того, государства обязуются проводить развитие сети школ всех ступеней, установить удовлетворительную систему стипендий и постоянно улучшать материальные условия преподавательского персонала.

В статье гарантируется свобода родителей (или иных законных опекунов) выбирать не только государственные, но и иные школы, которые, однако, должны отвечать минимальным образовательным стандартам, установленным или утвержденным государством, а также обеспечивать религиозное и нравственное воспитание своих детей в соответствии со своими собственными убеждениями. Часть 
четвертая вновь подтверждает право на создание частных учебных заведений, соответствующих минимальным государственным требованиям.

Особое значение в системе ООН придается противодействию дискриминации по различным основаниям, в том числе в сфере образования. Так, в соответствии со статьей 5 Международной конвенции о ликвидации всех форм расовой дискриминации ${ }^{5}$, принятой 21 декабря 1965 года и вступившей в силу 4 января 1969 г. «государства-участники обязуются запретить и ликвидировать расовую дискриминацию во всех ее формах и обеспечить равноправие каждого человека перед законом, без различия расы, цвета кожи, национального или этнического происхождения, в особенности в отношении»... «е) прав в экономической, социальной и культурной областях, в частности: ...v) права на образование и профессиональную подготовку».

В соответствии со статьей 10 Конвенции о ликвидации всех форм дискриминации в отношении женщин ${ }^{6}$ (принята 18 декабря 1979 г. и вступила в силу 3 сентября 1981 г.) государства осуществляют меры для ликвидации дискриминации в отношении женщин с целью обеспечения им равных с мужчинами прав в сфере образования и, в частности, «одинаковые условия для ориентации в выборе профессии или специальности, для доступа к образованию и получению дипломов в учебных заведениях всех категорий как в сельских, так и в городских районах (это равенство обеспечивается в дошкольном, общем, специальном и высшем техническом образовании, а также во всех видах профессиональной подготовки); доступ к одинаковым программам обучения, одинаковым экзаменам, преподавательскому составу одинаковой квалификации, школьным помещениям и оборудованию равного качества; устранение любой стереотипной концепции роли мужчин и женщин на всех уровнях и во всех формах обучения путем поощрения совместного обучения и других видов обучения, которые будут содействовать достижению этой цели, и, в частности, путем пересмотра учебных пособий и школьных программ

\footnotetext{
${ }^{5}$ Международная Конвенция о ликвидации всех форм расовой дискриминации (Нью-Йорк, 7 марта 1966 г.) // Ведомости Верховного Совета СССР. 1969. № 25. Ст. 219.

${ }^{6}$ Конвенция о ликвидации всех форм дискриминации в отношении женщин (Нью-Йорк, 18 декабря 1979 г.) // Ведомости Верховного Совета СССР. 1982. № 25 (2151). Ст. 464.
}

и адаптации методов обучения; одинаковые возможности получения стипендий и других пособий на образование; одинаковые возможности доступа к программам продолжения образования, включая программы распространения грамотности среди взрослых и программы функциональной грамотности, направленные, в частности, на сокращение как можно скорее любого разрыва в знаниях мужчин и женщин; сокращение числа девушек, не заканчивающих школу, и разработку программ для девушек и женщин, преждевременно покинувших школу; одинаковые возможности активно участвовать в занятиях спортом и физической подготовкой; доступ к специальной информации образовательного характера в целях содействия обеспечению здоровья и благосостояния семей, включая информацию и консультации о планировании размера семьи».

Конвенция о статусе апатридов 1954 г. предусматривает предоставление апатридам того же правового положения, что и гражданам Договаривающихся государств в отношении начального образования, и возможно более благоприятное правовое положение и, во всяком случае, положение, не менее благоприятное, чем то, которым обычно пользуются иностранцы при тех же обстоятельствах в отношении других видов народного образования, помимо начального, и в частности в отношении возможности учиться, признания иностранных аттестатов, дипломов и степеней, освобождения от платы за право учения и сборов, а также в отношении предоставления стипендий (статья 22).

Конвенция о статусе беженцев $1951 \Gamma^{8}{ }^{8}$ содержит аналогичные обязательства договаривающихся государств в отношении беженцев.

Уже Стандартные правила обеспечения равных возможностей для инвалидов ${ }^{9}$, принятые резолюцией 48/96 Генеральной Ассамблеи от

\footnotetext{
${ }^{7}$ Конвенция о статусе апатридов (Нью-Йорк, 28 сентября 1954 г.) // Текст Конвенции опубликован в сборнике «Действующее международное право» т. 1.

${ }^{8}$ Конвенция о статусе беженцев (Женева, 28 июля 1951 г.) // Текст Конвенции опубликован в журнале «Гражданин и право». 2002. № 6; в Бюллетене международных договоров от 1 ноября 1993 г. № 9; в сборнике «Действующее международное право» т. 1.

9 Резолюция Генеральной Ассамблеи ООН от 20 декабря 1993 г. № 48/96 «Стандартные правила обеспечения равных возможностей для инвалидов» (Текст Резолюции официально опубликован не был)
} 
20 декабря 1993 г., предусматривали признание государствами принципа равных возможностей в области начального, среднего и высшего образования для детей, молодежи и взрослых, имеющих инвалидность, в интегрированных структурах, а также признание образование инвалидов неотъемлемой частью системы общего образования. При этом ответственность за образование инвалидов в интегрированных структурах возлагалась на органы общего образования, предусматривалось обеспечение услуг переводчиков и других надлежащих вспомогательных услуг в обычных школах, привлечение родительских групп и организаций инвалидов к процессу образования на всех уровнях, а также обеспечение образования (в государствах, где оно признается обязательным) для детей обоего пола с различными формами и степенями инвалидности, включая самые тяжелые формы. Стандартные правила предусматривают уделение особого внимания детям самого юного возраста, являющимся инвалидами; детям-инвалидам дошкольного возраста; взрослым-инвалидам, особенно женщинам. Для обеспечения инвалидам возможностей в области образования в обычной школе государствам в соответствии с Правилами, следует иметь четко сформулированную политику, понимаемую и принимаемую на уровне школ и в более широких рамках общины; обеспечить гибкость учебных программ, возможность вносить в них добавление и изменение; предоставлять высококачественные учебные материалы, обеспечить на постоянной основе подготовку преподавателей и оказание им поддержки. Правила поощряют развитие совместного обучения и общинных программ, а также специальное обучение (когда система общего школьного образования все еще не удовлетворяет адекватным образом потребностям всех инвалидов), которое должно быть направлено на подготовку учащихся к обучению в системе общего школьного образования, при этом качество такого обучения должно отвечать тем же стандартам и целям, что и обучение в системе общего образования, и должно быть тесно с ним связано.

Более развитая система гарантий прав на образование закреплена в Конвенции о правах инвалидов $^{10} 2006$ г. В соответствии со статьей 24

\footnotetext{
${ }^{10} \mathrm{http}$ //www.un.org/russian/documen/convents/disability.html
}

«Образование» признается право инвалидов на образование. Государства обязуются без дискриминации и на основе равенства возможностей обеспечить «инклюзивное образование на всех уровнях и обучение в течение всей жизни, стремясь при этом: а) к полному развитию человеческого потенциала, а также чувства достоинства и самоуважения и к усилению уважения прав человека, основных свобод и человеческого многообразия; b) к развитию личности, талантов и творчества инвалидов, а также их умственных и физических способностей в самом полном объеме; с) к наделению инвалидов возможностью эффективно участвовать в жизни свободного общества».

При реализации этого права государства-участники «обеспечивают, чтобы: а) инвалиды не исключались по причине инвалидности из системы общего образования, а дети-инвалиды - из системы бесплатного и обязательного начального образования или среднего образования;

b) инвалиды имели наравне с другими доступ к инклюзивному, качественному и бесплатному начальному образованию и среднему образованию в местах своего проживания;

c) обеспечивалось разумное приспособление, учитывающее индивидуальные потребности;

d) инвалиды получали внутри системы общего образования требуемую поддержку для облегчения их эффективного обучения;

е) в обстановке, максимально способствующей освоению знаний и социальному развитию, сообразно с целью полной охваченности принимались эффективные меры по организации индивидуализированной поддержки».

Государства обеспечивают инвалидам возможность осваивать жизненные и социальные навыки с целью полного и равного участия в процессе образования и в качестве членов местного сообщества. Конвенция предусматривает дополнительные специальные меры как содействие освоению азбуки Брайля, альтернативных шрифтов, усиливающих и альтернативных методов, способов и форматов общения, а также навыков ориентации и мобильности и способствуют поддержке со стороны сверстников и наставничеству; содействуют освоению жестового языка и поощрению языковой самобытности глухих; в целом обеспечивать наиболее подходящие для индивида языки, методы и способы общения и обстановку, которая максимальным образом 
способствует освоению знаний и социальному развитию детей, которые являются слепыми, глухими или слепоглухими. Государства-участники принимают надлежащие меры для привлечения на работу компетентных учителей, в том числе учителей-инвалидов, и для обучения специалистов и персонала, работающих на всех уровнях системы образования. В соответствии с пунктом 5 инвалиды имеют право на доступ к общему высшему образованию, профессиональному обучению, образованию для взрослых и обучению в течение всей жизни без дискриминации и наравне с другими. С этой целью государства-участники обеспечивают, чтобы для инвалидов обеспечивалось «разумное приспособление».

16 декабря 1991 г. Генеральная Ассамблея приняла Принципы ООН в отношении пожилых людей ${ }^{11}$, которые призывают правительства признать, что пожилые люди должны иметь «возможность участвовать в соответствующих программах образования и профессиональной подготовки» и «доступ к возможностям общества в области образования, культуры, духовной жизни и отдыха».

В соответствии со ст. 30 Международной конвенции о защите прав всех трудящихся-мигрантов и членов их семей 1990 г. ${ }^{12}$ «Каждый ребенок трудящегося-мигранта имеет основное право на образование на основе равенства обращения с гражданами соответствующего государства. Не может быть отказано в посещении государственных дошкольных учебных заведений или школ, или ограничено это посещение по причине отсутствия постоянного статуса, в том что касается пребывания или занятости любого из родителей, или по причине отсутствия постоянного статуса, в том что касается пребывания такого ребенка в государстве работы по найму».

Наконец, согласно Основным принципам обращения с заключенными (приняты резолюцией 45/111

\footnotetext{
${ }^{11}$ Принципы Организации Объединенных Наций в отношении пожилых людей (Приняты 16.12.1991 г. Резолюцией 46/91 на 74-ом пленарном заседании 46-ой сессии Генеральной Ассамблеи ООН) // Документ опубликован не был; cм. http://www. un.org/russian/topics/socdev/elderly/oldprinc.htm

12 Международная конвенция о защите прав всех трудящихся-мигрантов и членов их семей (принята резолюцией 45/158 Генеральной Ассамблеи ООН от 18 декабря 1990 г.) // Конвенция не вступила в силу; Текст Конвенции размещен на официальном сервере Организации Объединенных Наций www.un.org
}

Генеральной Ассамблеи от 14 декабря 1990 г.) $)^{13}$ «все заключенные имеют право участвовать в культурной и образовательной деятельности, направленной на всестороннее развитие человеческой личности».

Одним из важнейших и наиболее широко признанных документов в системе ООН является Конвенция о правах ребенка 1989 г. ${ }^{14}$ Согласно статье 28, которая не только подтверждает соответствующие положения Всеобщей декларации права человека и Международного пакта об экономических, социальных и культурных правах, но и устанавливает дополнительные гарантии права на образование, государства-участники Конвенции подтверждают право ребенка на образование на основе равных возможностей. Вновь гарантируется бесплатное и обязательное начальное образование, а также введение бесплатного общего и профессионального среднего образования (и предоставление в необходимых случаях финансовой помощи) в различных формах. В то же время, в отношении высшего образования, в отличие от положений Пакта, Конвенция ограничивается обязательством обеспечения его всеобщей доступности на основе способностей каждого «с помощью всех необходимых средств» (не упоминая даже в качестве цели введение бесплатного высшего образования).

Конвенция устанавливает и ряд специальных норм об обеспечении доступности информации и материалов в области образования и профессиональной подготовки, о мерах по содействию регулярному посещению школ и снижению числа учащихся, покинувших школу, об обеспечении поддержания школьной дисциплины только с помощью методов, отражающих уважение человеческого достоинства ребенка, о поощрении и развитии международного сотрудничества по вопросам образования, в том числе «с целью содействия ликвидации невежества и неграмотности во всем мире и облегчения доступа к научно-техническим знаниям и современным методам обучения».

Статья 29 Конвенции о правах ребенка закрепляет гуманистические основы образования де-

\footnotetext{
13 Резолюция Генеральной Ассамблеи ООН от 14 декабря 1990 г. № 45/111 «Основные принципы обращения с заключенными» // Текст Резолюции приводится по изданию Организации Объединенных Наций (Нью-Йорк, 1992)

${ }^{14}$ Конвенция о правах ребенка (Нью-Йорк, 20 ноября 1989 г.) // Ведомости Съезда народных депутатов СССР и Верховного Совета СССР. 1990. № 45. Ст. 955.
} 
тей, которое должно быть направлено на развитие личности, талантов и умственных и физических способностей ребенка в их самом полном объеме; воспитание уважения к правам человека и основным свободам, а также принципам, провозглашенным в Уставе Организации Объединенных Наций; воспитание уважения к родителям ребенка, его культурной самобытности, языку и ценностям, к национальным ценностям страны, в которой ребенок проживает, страны его происхождения и к цивилизациям, отличным от его собственной; подготовку ребенка к сознательной жизни в свободном обществе в духе понимания, мира, терпимости, равноправия мужчин и женщин и дружбы между всеми народами, этническими, национальными и религиозными группами, а также лицами из числа коренного населения; воспитание уважения к окружающей природе.
При этом положения 28 и 29 статей гарантируют свободу отдельных лиц и органов создавать учебные заведения и руководить ими при условии постоянного соблюдения изложенных принципов и выполнения минимальных стандартов, установленных государством.

Таким образом, в системе ООН создана система универсальных международных стандартов в сфере образования, которая позволяет создать условия для реализации в универсальном масштабе права каждого на качественное и доступное образование. Россия как ответственный добросовестный субъект международного права ${ }^{15}$ должна не только строго соблюдать свои международно-правовые обязательства, но и содействовать развитию основ международного правопорядка, в том числе в такой значимой и перспективной для всего человечества сфере как образование.

\section{Библиография:}

1. Каламкарян Р.А., Мигачев Ю.И. Международное право как регулятор современных международно-правовых отношений // Государство и право. - 2013. - 11. - С. 46-59

2. Каламкарян Р.А. Россия в универсальном мировом правовом пространстве // Государство и право. 2013. - 11. - C. $75-85$

3. Комаров В.В. Образование в ландшафте ООН // Экономика образования. 2013. № 5 (78). С. 12-23

4. Арапов А.В.. Глобальное управление: концепции и тенденции // Международные отношения. - 2014. - № 1. - C. 104-107. DOI: 10.7256/2305-560Х.2014.1.9687

5. Новичкова Г.А.. Культура образования и социализация как две составляющие человеческого бытия // Педагогика и просвещение. - 2013. - № 3. - С. 234-246. DOI: 10.7256/2306-434X.2013.3.9731.

6. П.С. Гуревич. Образование и будущее человека // Педагогика и просвещение. - 2013. - № 2. - C. 104-113. DOI: $10.7256 / 2306-434 X .2013 .2 .9123$.

7. Кананыкина Е.С. Система французского высшего образования // NB: Административное право и практика администрирования. - 2013. - № 8. -C.57-81. DOI: 10.7256/2306-9945.2013.8.687. URL: http://e-notabene.ru/ al/article_687.html

8. Э.М. Спирова. Как формировалась идея воспитания? // Педагогика и просвещение. - 2013. - № 1. - С. 53-59. DOI: 10.7256/2306-434X.2013.01.6.

9. Урсул А.Д., Урсул Т.А. Наука и образование в глобально-ноосферной перспективе // NB: Проблемы общества и политики. - 2013. - № 2. - C.161-222. DOI: 10.7256/2306-0158.2013.2.439. URL: http://e-notabene. $\mathrm{ru} / \mathrm{pr} /$ article_439.html

10. И.Н. Сиземская. Проблемы образования в контексте отечественного философско-педагогического наследия // Педагогика и просвещение. - 2012. - № 3. - С. 7-15.

11. Кананыкина Е.С. Правовой аспект глобализации системы образования стран Латинской Америки // NB: Административное право и практика администрирования. - 2013. - № 10. - C.89-165. DOI: 10.7256/23069945.2013.10.780. URL: http://e-notabene.ru/al/article_780.html

\footnotetext{
${ }^{15}$ Каламкарян Р.А. Россия в универсальном мировом правовом пространстве // Государство и право. - 2013. - 11. - С. 75-85
} 
12. Е.О. Труфанова, О.Р. Яновская. Институт образования в обществе знаний // Педагогика и просвещение. - 2012. - № 3. - С. 30-43.

13. А.Д. Урсул. Процесс футуризации и становление опережающего образования // Педагогика и просвещение. - 2012. - № 2. - С. 20-33.

14. О.Е. Баксанский. Конвергентный подход к философии образования // Педагогика и просвещение. - 2012. - № 1. - С. 10-15.

15. Урсул А.Д., Урсул Т.А. Образование как информационный процесс и перспективы его футуризации // NB: Педагогика и просвещение. - 2013. - № 2. - C.1-57. DOI: 10.7256/2306-4188.2013.2.8997. URL: http://e-notabene.ru/pp/article_8997.html

16. Розин В.М. Становление новой образовательной формации // NB: Педагогика и просвещение. -2013. - № 1. - C.1-43. DOI: 10.7256/2306-4188.2013.1.6445. URL: http://e-notabene.ru/pp/article_6445.html

17. Е.А. Попов. Современная социология и человек: грани объективации мира в науке и образовании // Педагогика и просвещение. - 2012. - № 1. - С. 36-41.

18. Човган И.В. Анализ влияния процесса глобализации на обеспечение национальной безопасности государства в сфере высшего образования // NB: Вопросы права и политики. - 2013. - № 5. - C.135-149. DOI: 10.7256/2305-9699.2013.5.739. URL: http://e-notabene.ru/lr/article_739.htm

19. Кананыкина Е.С. Источники права об образовании в социалистической системе Китая // NB: Проблемы общества и политики. - 2013. - 6. - С. 137 - 158. DOI: 10.7256/2306-0158.2013.6.456. URL: http://www.e-notabene.ru/pr/article_456.html

\section{References (transliteration):}

1. Kalamkaryan R.A., Migachev Yu.I. Mezhdunarodnoe pravo kak regulyator sovremennykh mezhdunarodno-pravovykh otnoshenii // Gosudarstvo i pravo. - 2013. - 11. - S. 46-59

2. Kalamkaryan R.A. Rossiya $\mathrm{v}$ universal'nom mirovom pravovom prostranstve // Gosudarstvo i pravo. - 2013.11. - S. 75-85

3. Komarov V.V. Obrazovanie v landshafte OON // Ekonomika obrazovaniya. 2013. № 5 (78). S. 12-23

4. Arapov A.V.. Global'noe upravlenie: kontseptsii i tendentsii // Mezhdunarodnye otnosheniya. - 2014. - № 1. - S. 104-107. DOI: 10.7256/2305-560X.2014.1.9687

5. Novichkova G.A.. Kul'tura obrazovaniya i sotsializatsiya kak dve sostavlyayushchie chelovecheskogo bytiya // Pedagogika i prosveshchenie. - 2013. - № 3. - S. 234-246. DOI: 10.7256/2306-434X.2013.3.9731.

6. P.S. Gurevich. Obrazovanie i budushchee cheloveka // Pedagogika i prosveshchenie. - 2013. - № 2. - S. 104-113. DOI: 10.7256/2306-434Kh.2013.2.9123.

7. Kananykina E.S. Sistema frantsuzskogo vysshego obrazovaniya // NB: Administrativnoe pravo i praktika administrirovaniya. - 2013. - № 8. -S.57-81. DOI: 10.7256/2306-9945.2013.8.687. URL: http://e-notabene.ru/al/ article_687.html

8. E.M. Spirova. Kak formirovalas’ ideya vospitaniya? // Pedagogika i prosveshchenie. - 2013. - № 1. - S. 53-59. DOI: 10.7256/2306-434Kh.2013.01.6.

9. Ursul A.D., Ursul T.A. Nauka i obrazovanie v global'no-noosfernoi perspektive // NB: Problemy obshchestva i politiki. - 2013. - № 2. - S.161-222. DOI: 10.7256/2306-0158.2013.2.439. URL: http://e-notabene.ru/pr/article_439.html

10. I.N. Sizemskaya. Problemy obrazovaniya v kontekste otechestvennogo filosofsko-pedagogicheskogo naslediya // Pedagogika i prosveshchenie. - 2012. - № 3. - S. 7-15.

11. Kananykina E.S. Pravovoi aspekt globalizatsii sistemy obrazovaniya stran Latinskoi Ameriki // NB: Administrativnoe pravo i praktika administrirovaniya. - 2013. - № 10. - S.89-165. DOI: 10.7256/23069945.2013.10.780. URL: http://e-notabene.ru/al/article_780.html

12. E.O. Trufanova, O.R. Yanovskaya. Institut obrazovaniya v obshchestve znanii // Pedagogika i prosveshchenie. - 2012. - № 3. - S. 30-43. 
DOI: $10.7256 / 2226-6305.2014 .2 .11895$

При цитировании этой статьи сноска на dоі обязательна

Международное право и международные организации International Law and International Organizations

13. A.D. Ursul. Protsess futurizatsii i stanovlenie operezhayushchego obrazovaniya // Pedagogika i prosveshchenie. -2012 . - № 2. - S. 20-33.

14. O.E. Baksanskii. Konvergentnyi podkhod k filosofii obrazovaniya // Pedagogika i prosveshchenie. - 2012. № 1. - S. 10-15.

15. Ursul A.D., Ursul T.A. Obrazovanie kak informatsionnyi protsess i perspektivy ego futurizatsii // NB: Pedagogika i prosveshchenie. - 2013. - № 2. - S.1-57. DOI: 10.7256/2306-4188.2013.2.8997. URL: http://e-notabene.ru/pp/ article_8997.html

16. Rozin V.M. Stanovlenie novoi obrazovatel'noi formatsii // NB: Pedagogika i prosveshchenie. - 2013. - № 1. S.1-43. DOI: 10.7256/2306-4188.2013.1.6445. URL: http://e-notabene.ru/pp/article_6445.html

17. E.A. Popov. Sovremennaya sotsiologiya i chelovek: grani ob"'ektivatsii mira v nauke i obrazovanii // Pedagogika i prosveshchenie. - 2012. - № 1. - S. 36-41.

18. Chovgan I.V. Analiz vliyaniya protsessa globalizatsii na obespechenie natsional'noi bezopasnosti gosudarstva v sfere vysshego obrazovaniya // NB: Voprosy prava i politiki. - 2013. - № 5. - S.135-149. DOI: 10.7256/23059699.2013.5.739. URL: http://e-notabene.ru/lr/article 739.htm

19. Kananykina E.S. Istochniki prava ob obrazovanii v sotsialisticheskoi sisteme Kitaya // NB: Problemy obshchestva i politiki. - 2013. - 6. - C. 137 - 158. DOI: 10.7256/2306-0158.2013.6.456. URL: http://www.e-notabene.ru/pr/ article_456.html 